\title{
Formulation and Evaluation of Sustained Release Glipizide Matrix
}

\author{
${ }^{1}$ Kambham Venkateswarlu, ${ }^{2}$ A. SHANTHI \\ ${ }^{1,2}$ Sri Lakshmi Narasimha College of Pharmacy, India.
}

\section{Introduction:}

Increased complications and expense involved in marketing of new drug entities has focused greater attention on development of sustained release (SR) or controlled release(CR) drug delivery systems. Sustained or controlled release delivery systems can achieve predictable and reproducible release rates, extended duration of activity for short half - life drugs, decreased toxicity, and reduction of required dose, optimized therapy and better patient compliance. Matrix type sustained delivery systems are popular because of their ease of manufactures. It excludes complex production procedure such as coating and pellitization during manufacturing and drug release from the dosage form. It is controlled mainly by the type and proportion of the polymers used in the preparation.

Eudragit RL-100 is copolymer of acrylic and methacrylic esters with a low content in quaternary ammonium group. The ammonium groups are present as salts and make the polymers permeable. It is used as a film farming agent, tablet binder, tablet diluents.

Ethyl Cellulose is used as a coating agent, flavoring agent, tablet binder, table filler, viscosity increasing agent. It is stable, slightly hygroscopic material chemically resistant to alkali but sensitive to acidic material.

Microcrystalline Cellulose (MCC) is a pharmaceutical aid and widely used as a diluents or binder in oral tablets and capsule formation. It also has a disintegrant and lubricant property so it makes useful in tableting. It is a stable though hygroscopic material.

Magnesium stearate is used as a lubricant in capsule and tablet manufacture at concentration between 0.25 and $5.0 \%$.

Talc is a purified hydrated magnesium silicate and used as a anti cacking agent, glidant, tablet and capsule diluents, tablet and capsule lubricant. It is widely used as a dissolution retardant in the development of controlled-release products. It is also used as a dusting powder.

Glipizide is an oral hypoglycemic agent, which is a commonly prescribed drug for the treatment of patients with type II diabetes. It is used adjunct to diet to the management of type II (non-insulin dependent) diabetes mellitus in patients whose hyperglycemia cannot be controlled by diet and exercise alone. Glipizide stimulates insulin secretion from the $\beta$ cells of pancreatic islets tissue, increases the concentration of insulin in the pancreatic vein and may increase the number of insulin receptors. Glipizide is a weak acid $(\mathrm{pKa}=5.9)$ practically insoluble in water and acidic environment and highly permeable (class II) drugs according to the Biopharmaceutical Classification System (BCS). The oral absorption is uniform, rapid and complete with a bioavailability of nearly $100 \%$ and an elimination half-life of 2- 4 hours. Glipizide is reported to have a short biological half-life $(3.4 \pm 0.7 \mathrm{~h})$ requiring it to be administered in 2 to 3 doses of 2.5 to $10 \mathrm{mg}$ per day. SR formulations that would maintain plasma levels of drug for 8 to $12 \mathrm{hrs}$ might be sufficient for once a day dosing for Glipizide. SR products are needed for glipizide to prolong its duration of action and to improve patient compliance.

\section{Sustained Release Drug Delivery System:}

Sustained Release Drug Delivery system is the one, which delivers the drug for a prolonged time, locally or systemically.

Merits:

a) Increased safety margin of high potency drugs due to better control of plasma levels.

b) Maximum utilization of drug enabling reduction in total amount of dose administered.

c) Reduction in fluctuations in steady levels and therefore better control of disease condition and reduced intensity Of local or systemic effects.

Demerits:

a) Poor in vitro-in vivo correlation.

b) Retrieval of drug is difficult in case of toxicity, poisoning or hypersensitivity reactions.

c) Reduced potential for dosage adjustment of drug normally administered in varying strength. 
d) Possibility of dose dumping.

e) Higher cost of formulation.

f)

1.1) TYPES OF SUSTAINED RELEASE SYSTEM:

1.1.1) Dissolution Controlled Release System

1.1.2) Diffusion Controlled Release System

1.1.3) Bio-Erodible and Combination Diffusion and Dissolution System

1.1.4) Osmotically Controlled Release System

1.1.5) Ion Exchange Systems

\section{2) MATRIX DEVICES:}

It comes under Diffusion Controlled Release System.

Diffusion Controlled Device consists of 1.2.1) Rigid Matrix

1.2.2) Swellable Matrix

This system, a solid drug is dispersed in lipophilic or hydrophilic polymer matrix and the rate of release of drug depends on the rate of drug diffusion and not on the rate of solid dissolution.

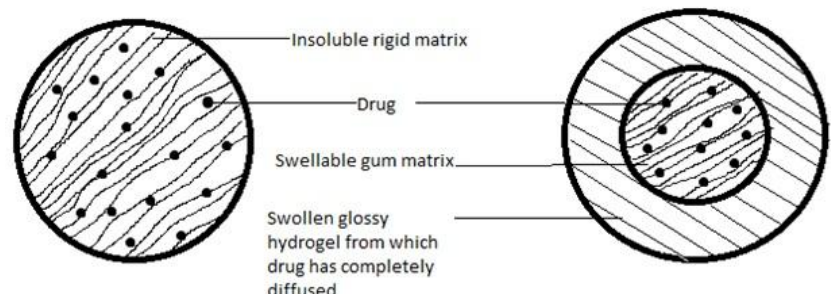

A) RIGID MATRIX

B) SWELLABLE MATRIX

\section{2) DRUG PROFILE -GLIPIZIDE:}

Chemical Name: N-[2-[4-(cyclohexylcarbamoylsulfamoyl)phenyl]ethyl]-5-methyl-pyridine-2-carboxamide

Water Solubility: $37.2 \mathrm{mg} / \mathrm{L}$

Empirical Formula: $\mathrm{C}_{21} \mathrm{H}_{27} \mathrm{~N}_{5} \mathrm{O}_{4} \mathrm{~S}$

Molecular Weight : $445.5350 \mathrm{~g} / \mathrm{mol}$

Biopharmaceutical classification system: Class-2 (High Permeability \& low solubility)<smiles>Cc1cnc(C(=O)NCCc2ccc(S(=O)(=O)NC(=O)NC3CCCCC3)cc2)cn1</smiles>

\section{1) PHARMACEUTICAL PROFILE:}

Dosage form: Tablet of strength 5-15 mg

\section{2) PHARMACOLOGICAL PROFILE:}

2.3.1) Pharmacology:

Sustained Release Drug Delivery System aims to deliver the drugs for a prolonged time, locally or systemically. The Glipizide is a second generation sulfonylureas which is used with diet to lower the blood glucose in patients with the diabetic mellitus- 2 .

\subsection{2) Mode Of Action:}

The primary action of the glipizide is a stimulation of insulin secretion from the beta-cells of the pancreatic tissue; Reduces the glucose output from the Liver; insulin sensitivity is increased at peripheral target sites.

\subsection{3) Pharmacodynamics / Kinetics:}

Duration: $12-24$ hours

Absorption: Rapid and complete; delayed with food.

Distribution: $10-11 \mathrm{~L}$

Protein binding: $98 \%$ to $99 \%$; primarily to albumin

Bioavailability: $90 \%$ to 100

Metabolism: Hepatic via CYP2C9;forms metabolites (inactive)

Half-life elimination: $2-5$ hours 
Time to peak: 1-3 hours: extended release tablets: 6-12 hoursExcretion: Urine (60\% to80\%, 91\% to97\% as metabolites); feces (11\%)

\subsection{4) Indications And Dosages:}

To control blood glucose in type-2 (non-insulin-dependent) diabetes mellitus in patients who have some pancreatic function and don't respond to diet therapy.

Adults: $5 \mathrm{mg}$ /day P.O. initially, increased as needed after several days (range is 2.5 to $40 \mathrm{mg} /$ day). Give extended-release tablets once daily; maximum dosage is $20 \mathrm{mg}$ /day. Give daily dosage above 15 in two divided doses.

Conversion from insulin therapy

Adults: with insulin dosage above 20units/day, start with usual Glipizide dosage and reduce insulin dosage by $50 \%$. With insulin dosage of 20 units/day or less, insulin may discontinued when Glipizide therapy starts.

3.1) Eudragit RL-100

III. Polymers:

3.2) Ethyl Cellulose

3.3) Microcrystalline Cellulose

3.4) Magnesium stearate

3.5) Talc

Polymers were received from Aravind Remedies (AR), Chennai.

\section{Process And Development:}

4.1) Preparation of Glipizide matrix tablets with combination of EUDRAGIT RL-100 and ETHYL CELLULOSE:

Matrix tablets were prepared by direct compression method. Glipizide RL-100 (10mg) was blended with appropriate quantity of polymer in combination of Eudragit RL-100, Ethyl Cellulose. The dilute Microcrystalline Cellulose ratio varies with the concentration polymers and was blended thoroughly in the polybag and the powder was passed through sieve no.14. then the mixture was blended with $1 \%$ Magnesium stearate and $2 \%$ Talc and mixed for 5 minutes. This mixture was compressed using station rotary tabletting machine with flat punch of $8 \mathrm{~mm}$ diameter.

The compositions of tablets were varied by using polymer and MCC in different ratios and were represented in table:

\begin{tabular}{|l|l|l|l|l|l|l|}
\hline FORMULA & F1 & F2 & F3 & F4 & F5 & F6 \\
\hline DRUG (mg) & 10 & 10 & 10 & 10 & 10 & 10 \\
\hline $\begin{array}{l}\text { Eudragit RL- } \\
100(\mathrm{mg})\end{array}$ & 60 & 70 & 80 & 80 & 80 & 80 \\
\hline $\begin{array}{l}\text { Ethyl Cellulose } \\
(\mathrm{mg})\end{array}$ & 80 & 70 & 60 & 50 & 45 & 40 \\
\hline $\begin{array}{l}\text { Microcrystalline } \\
\text { Cellulose (mg) }\end{array}$ & 44 & 46 & 50.5 & 54 & 57 & 59 \\
\hline $\begin{array}{l}\text { Magnesium } \\
\text { stearate }\end{array}$ & $1 \%$ & $1 \%$ & $1 \%$ & $1 \%$ & $1 \%$ & $1 \%$ \\
\hline Talc & $2 \%$ & $2 \%$ & $2 \%$ & $2 \%$ & $2 \%$ & $2 \%$ \\
\hline Total & 200 & 200 & 200 & 200 & 200 & 200 \\
\hline
\end{tabular}

All the formulation has Talc $2 \%$ as glidant and Magnesium Stearate $1 \%$ as a lubricant.

Total weight of tablet is $200 \mathrm{mg}$.

\section{1) CONSTRUCTION OF STANDARD GRAPH OF GLIPIZIDE}

\section{Evaluation Of Glipizide Matrix Tablets:}

An accurately weighed amount of $100 \mathrm{mg}$ Glipizide was transferred into a $100 \mathrm{ml}$ volumetric flask and volume was made up to $100 \mathrm{ml}$ with $7.4 \mathrm{pH}$ phosphate buffer. The resulted solution had the concentration of $1 \mathrm{mg} / \mathrm{ml}$ which was labeled as stock solution 1 from this stock solution $10 \mathrm{ml}$ was taken and diluted to $100 \mathrm{ml}$ with $7.4 \mathrm{pH}$ phosphate buffer which has given the solution having the concentration of $100 \mu \mathrm{g} / \mathrm{ml}$ which was labeled as stock-2.

Necessary dilution were made by using second solution to give the different concentration of Glipizide $10-100 \mu \mathrm{g}$ solutions can be made. 
The volumetric solution $10 \mu \mathrm{g} / \mathrm{ml}$ was scanned in a UV-Visible double beam spectrophotometer to determine the $\lambda$ max of the drug. The absorbance of the volumetric solution was recorded at $\lambda$ max of the drug and plotted graphically to the standard graph of Glipizide.

\section{Preparation of ph 7.4 phophate buffer:}

An accurately measured $50 \mathrm{ml}$ of $0.2 \mathrm{M}$ potassium dihydrogen orthophosphate was transferred to a $200 \mathrm{ml}$ volumetric flask and $39.14 \mathrm{ml}$ of $0.2 \mathrm{M}$ sodium hydroxide was added to it. Volume was made up to $200 \mathrm{ml}$ with distilled water, mixed and $\mathrm{pH}$ was adjusted to 7.4 with $0.2 \mathrm{M}$ sodium hydroxide or $0.2 \mathrm{M}$ orthophophoric acid.

Preparation of potassium dihydrogen phosphate:

An accurately weighed $27.21 \mathrm{~g}$ of monobasic potassium dihydrogen phosphate was dissolved in $1000 \mathrm{ml}$ of distilled water and mixed.

\section{Preparation of sodium hydroxide solution:}

An Accurately weighted $8 \mathrm{gm}$ of sodium hydroxide pellets were dissolved in $1000 \mathrm{ml}$ of distilled water and mixed.

\section{2) PHYSICAL PROPERTIES OF MATRIX TABLETS:}

\subsection{1) Tablet Thickness:}

Six tablets from the representative sample were randomly taken and individual tablet thickness was measured by using digital vernier calipers. Average thickness and standard deviation values were calculated.

\subsection{2) Tablet Hardness:}

Tablet hardness was measured by using Monsanto hardness tester. From each batch the crushing strength of six tablets with known weights and thickness of each recorded in $\mathrm{kg} / \mathrm{cm}^{2}$ were measured for the hardness and average hardness and standard deviation was reported.

\subsection{3) Friability Test:}

From each batch, twenty tablets were accurately weighed and placed in the friability test apparatus (Roche friabilator). Apparatus was operated at $25 \mathrm{rpm}$ for $4 \mathrm{mins}$ and tablets were observed while rotating. The tablets were then taken after 100 rotations, retested and reweighed. The friability was calculated as the percentage weight loss.

$\%$ friability was calculated as follows:

Where

$\%$ friability $=\left(\mathrm{W}_{1}-\mathrm{W}_{2}\right) \mathrm{X} 100 / \mathrm{W}_{1}$

$\mathrm{W}_{1}=$ initial weight of the 20 tablets

$\mathrm{W}_{2}=$ final weight of the 20 tablets after testing

Friability values below $0.8 \%$ are generally acceptable.

\subsection{4) Weight Variation Test:}

To study weight variation individual weights $\left(\mathrm{W}_{1}\right)$ of 20 tablets from each formulation were noted using electronic balance. Their average weights $\left(\mathrm{W}_{\mathrm{A}}\right)$ ware calculated. the Percentage weight variation was calculated as follows. Average weights of the tablets along with standard deviation values were calculated.

$\%$ weight variation $=\left(\mathrm{W}_{\mathrm{A}}-\mathrm{W}_{1}\right) \times 100 / \mathrm{W}_{\mathrm{A}}$

\subsection{5) Drug Content (Assay):}

The drug content of the matrix tablets was determined by standards and it meets the requirements if the amount of the active ingredient in each of 10 tested tablets lies within the range of $90 \%$ to $110 \%$ of the standard amount.

Ten tablets were weighed and taken into a mortar and crushed into fine powder.

An accurately weighed portion of the powder equivalent to about $10 \mathrm{mg}$ of Glipizide was transferred to $100 \mathrm{ml}$ volumetric flask containing $70 \mathrm{ml}$ of $7.4 \mathrm{pH}$ phosphate buffer. It was shaken by mechanical means for $1 \mathrm{hr}$ then it was filtered through Watsmann filter paper (no.1) and diluted to $100 \mathrm{ml}$ with $7.4 \mathrm{pH}$ phosphate buffer. From this resulted solution $1 \mathrm{ml}$ was taken, diluted to $50 \mathrm{ml}$ with $7.4 \mathrm{pH}$ phosphate buffer and absorbance was measured against blank at $223 \mathrm{~nm}$.

\section{3) IN-VITRO DRUG RELEASE CHARACTERISTICS:}

The dissolution studies were performed for the formulated Glipizide tablets over a period of 12 hours using USP dissolution test apparatus.

Drug release was assayed by dissolution test under the following conditions: $n=3$ USP type II dissolution apparatus (paddle method) at 50rpm $900 \mathrm{ml}$ of phosphate buffer $\mathrm{pH} 6.8$ for 12 hours, maintained at 
$\left(37^{0} \pm 0.5^{0} \mathrm{c}\right)$ fresh dissolution medium. The samples withdrawn were filtered through Watsmann Filter Paper (No.1) and drug content in each sample was analyzed by UV-visible spectrophotometer at $223 \mathrm{~nm}$.

6.1)

VI. Result And Discussion:

STANDARD GRAPH OF GLIPIZIDE:

The scanning of $2.5 \mu \mathrm{g} / \mathrm{ml}$ of the volumetric solution of Glipizide in the UV range against deionised water and $\mathrm{pH} 7.4$ phosphate buffer determined the lambda max of the absorbance at $223 \mathrm{~nm}$. The standard graph of Glipizide has shown good linearity with $\mathrm{R}^{2}$ value 0.9984 which suggest that obeys the Beer-Lamberts law.

\begin{tabular}{|l|l|}
\hline $\begin{array}{l}\text { Concentration } \\
(\boldsymbol{\mu g} / \mathbf{m l})\end{array}$ & $\begin{array}{l}\text { Absorbance } \\
(\mathbf{n m})\end{array}$ \\
\hline 2.5 & 0.124 \\
\hline 5 & 0.264 \\
\hline 7.5 & 0.405 \\
\hline 10 & 0.548 \\
\hline 12.5 & 0.663 \\
\hline 15 & 0.828 \\
\hline
\end{tabular}

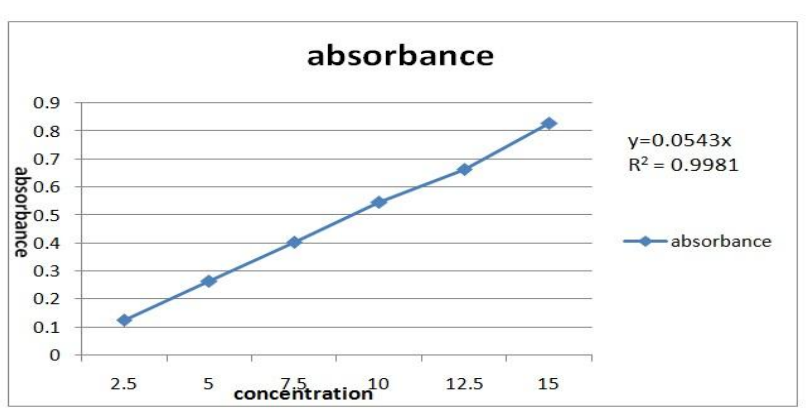

Fig,1 Standard graph of Glipizide in 7.4 pH Phosphate buffer

6.2) PHYSICAL EVALUATION OF MATRIX TABLETS:

\begin{tabular}{|l|l|l|l|l|l|}
\hline $\begin{array}{c}\text { F } \\
\text { Code }\end{array}$ & $\begin{array}{l}\text { Hardness } \\
\left(\mathbf{K g} / \mathbf{c m}^{2}\right)\end{array}$ & $\begin{array}{l}\text { Thickness } \\
(\mathbf{m m})\end{array}$ & $\begin{array}{l}\text { Weight } \\
\text { variation(mg) }\end{array}$ & $\begin{array}{l}\text { Friability } \\
\text { \% }\end{array}$ & $\begin{array}{l}\text { Drug content } \\
\text { \% }\end{array}$ \\
\hline F1 & $5.1 \pm 0.236$ & $2.23 \pm 0.078$ & $200.71 \pm 2.87$ & $0.29 \pm 0.15$ & $93.28 \pm 1.99$ \\
\hline F2 & $5.04 \pm 0.104$ & $2.19 \pm 0.053$ & $200.42 \pm 1.35$ & $0.32 \pm 0.09$ & $95.35 \pm 1.14$ \\
\hline F3 & $5.06 \pm 0.185$ & $2.22 \pm 0.087$ & $199.9 \pm 1.33$ & $0.17 \pm 0.13$ & $96.34 \pm 2.18$ \\
\hline F4 & $5.1 \pm 0.109$ & $2.22 \pm 0.074$ & $200 \pm 1.54$ & $0.19 \pm 0.07$ & $91.29 \pm 0.98$ \\
\hline F5 & $5.1 \pm 0.167$ & $2.18 \pm 0.087$ & $200.4 \pm 1.45$ & $0.24 \pm 0.07$ & $97.35 \pm 0.43$ \\
\hline F6 & $5.04 \pm 0.09$ & $2.17 \pm 0.078$ & $200.2 \pm 1.6$ & $0.22 \pm 0.14$ & $98.88 \pm 0.88$ \\
\hline
\end{tabular}

The result in uniformity of the weight, hardness, Thickness, Friability, Drug content of the tablets are shown in the above table. All the tablets of the different batches compiled with the official requirements of uniformity of weight as the weights varied between $200.71 \pm 1.02$ to $199 \pm 1.33 \mathrm{mg}$. the Hardness of the tablets ranged from $5.1 \pm 0.236$ to $5.04 \pm 0.09 \mathrm{~kg} / \mathrm{cm}^{2}$.

The friability values were less than $0.8 \%$ indicating that the matrixes were compact and hard. The thickness of the tablets ranged from $2.17 \pm 0.078$ to $2.23 \pm 0.078 \mathrm{~mm}$.

All the formulations satisfied the contents of the drug as they contained above $91.29 \pm 0.98 \%$ of Glipizide and good uniformity in drug content was observed. Thus all the physical attributes of the prepared were found to be practically within official limit.

6.3) Matrix Formulation By The Combination Of The Ethyl Cellulose And Eudragit Rl100 In Powder Form By Direct Compression:

In vitro Drug Release Of Glipizide From The Combination of Eudrgit rl 100 and Ethyl Cellulose Matrices:

\begin{tabular}{|l|l|l|l|l|l|l|}
\hline $\begin{array}{l}\text { Time } \\
\text { (hr) }\end{array}$ & F1(40\%EC) & F2(35\%EC) & F3(30\%EC) & F4(25\%EC) & F5(22.5\%EC) & F6(20\%EC) \\
\hline $\mathbf{0}$ & 0 & 0 & 0 & 0 & 0 & 0 \\
\hline $\mathbf{0 . 5}$ & $0.83 \pm 0.9$ & $0.91 \pm 0.3$ & $1.83 \pm 0.5$ & $2.33 \pm 0.9$ & $3.83 \pm 0.2$ & $6.84 \pm 1.1$ \\
\hline $\mathbf{1}$ & $3.51 \pm 0.6$ & $5.67 \pm 1.1$ & $6.01 \pm 1.1$ & $7.18 \pm 0.7$ & $9.45 \pm 1.1$ & $14.25 \pm 1.5$ \\
\hline
\end{tabular}


Formulation And Evaluation Of Sustained Release Glipizide Matrix

\begin{tabular}{|l|l|l|l|l|l|l|}
\hline \hline $\mathbf{2}$ & $7.52 \pm 0.8$ & $8.86 \pm 0.7$ & $10.71 \pm 1.7$ & $12.54 \pm 1.1$ & $16.45 \pm 1.8$ & $23.65 \pm 0.3$ \\
\hline $\mathbf{3}$ & $10.88 \pm 1.4$ & $15.22 \pm 1.1$ & $14.91 \pm 0.6$ & $17.12 \pm 0.5$ & $22.14 \pm 1.4$ & $32.51 \pm 2.1$ \\
\hline $\mathbf{4}$ & $13.91 \pm 1.2$ & $18.26 \pm 1.4$ & $18.26 \pm 1.7$ & $23.14 \pm 2.5$ & $31.12 \pm 0.8$ & $43.15 \pm 0.8$ \\
\hline $\mathbf{5}$ & $18.94 \pm 1.1$ & $19.63 \pm 0.8$ & $22.63 \pm 2.3$ & $29.14 \pm 0.8$ & $37.21 \pm 0.5$ & $52.14 \pm 0.3$ \\
\hline $\mathbf{6}$ & $20.98 \pm 1.3$ & $22.99 \pm 1.3$ & $29.34 \pm 1.3$ & $34.24 \pm 0.7$ & $42.14 \pm 2.1$ & $60.54 \pm 0.7$ \\
\hline $\mathbf{7}$ & $24.68 \pm 0.7$ & $26.21 \pm 0.9$ & $32.91 \pm 1.8$ & $39.98 \pm 1.1$ & $46.89 \pm 1.2$ & $67.24 \pm 0.5$ \\
\hline $\mathbf{8}$ & $26.72 \pm 1.1$ & $30.91 \pm 1.1$ & $35.79 \pm 0.7$ & $45.31 \pm 0.5$ & $52.64 \pm 1.5$ & $72.45 \pm 2.5$ \\
\hline $\mathbf{9}$ & $29.76 \pm 2.1$ & $33.81 \pm 1.8$ & $38.51 \pm 1.9$ & $48.21 \pm 1.5$ & $56.21 \pm 2.9$ & $78.14 \pm 0.7$ \\
\hline $\mathbf{1 0}$ & $32.31 \pm 0.8$ & $37.18 \pm 1.6$ & $40.91 \pm 1.1$ & $53.14 \pm 0.8$ & $61.54 \pm 1.2$ & $81.41 \pm 3.1$ \\
\hline $\mathbf{1 1}$ & $35.85 \pm 1.6$ & $40.91 \pm 2.3$ & $43.62 \pm 0.7$ & $57.12 \pm 1.9$ & $67.15 \pm 2.1$ & $85.12 \pm 1.7$ \\
\hline $\mathbf{1 2}$ & $39.41 \pm 1.8$ & $43.96 \pm 0.9$ & $46.01 \pm 0.8$ & $63.15 \pm 1.2$ & $72.31 \pm 1.1$ & $88.21 \pm 1.8$ \\
\hline
\end{tabular}

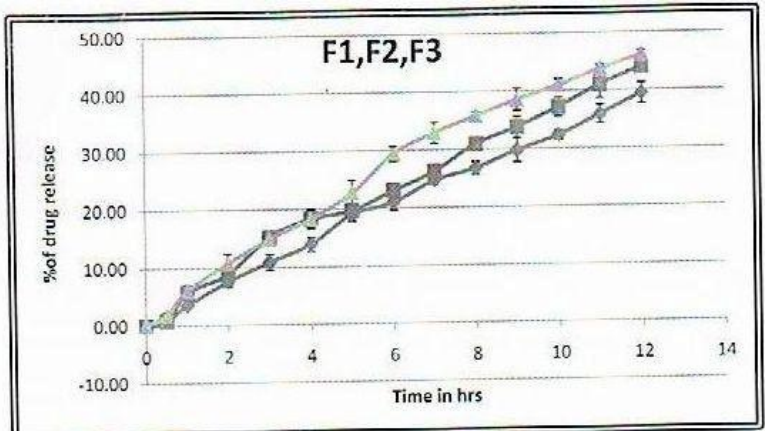

Fig.2 shows F1, F2, F3 \% drug release from Edragit RL 100 and Ethyl Cellulose

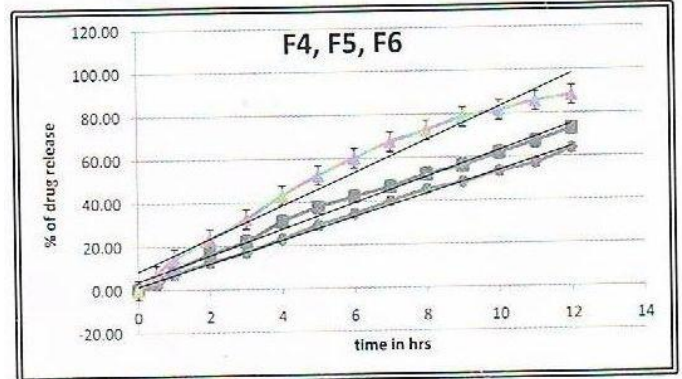

Fig.3 shows F4, F5, F6 \% drug release Eudragit RL 100 and Ethyl Cellulose.

The result of $\%$ drug release of formulations $\mathrm{F} 1$ to $\mathrm{F} 3$ shows $39.41 \pm 1.8$ up to $46.01 \pm 0.8$ were produced by the composition of Eudragit RL 100 in increasing concentration and by altering Ethyl Cellulose concentration $(25,22.5,20 \%)$ for F4 to F6 with same concentration of Eudragit RL $100(80 \mathrm{mg})$ are taken with increasing the MCC concentration. the result of \% drug release study shows from $63.15 \pm 1.2$ to $88.21 \pm 1.8$. As Ethyl Cellulose acts as tablet binder and MCC concentration increases to $32 \%$ it act as tablet disintegrating agent lose of integrity takes place.

As the amount of Ethyl Cellulose polymer from F1 to F6 decreases a significant increase in the rate and extent of the drug release was observed in F4 toF6 when compared to F1 to F3.

\section{Conclusion:}

Matrix tablets of Gipizide with combination of hydrophobic polymers Eudragit RL100 (Powder form) and ethyl cellulose were developed by direct compression method. The results of this study enable us to state that combination of these polymers with various proportions does not affects the drug release and thus the matrix tablet formulation will be the effective pharmaceutical formulations.

The objective of this study was to develop Matrix Tablets of Glipizide with different Polymers Eudragit RL 100 and Ethyl Cellulose and the study of influence of polymer of the drug release.

Then the formulation shifted to Eudragit RL 100 Combination with ethyl cellulose. First 3 formulations of F1, F2, F3 shows the slow release of drug due to higher concentration of ethyl cellulose and increasing the MCC from F1 to F6 and maintaining the concentration of Eudragit RL 100 for F4, F5, and F6 formulations drug release up to $12 \mathrm{hrs}$ was about 81.41 to $88.8 \%$.

The development was initiated with standard calibration curve using UV Spectrophotometric method as it is required to routine analysis of drug. The UV Spectrophotometric method was developed in $7.4 \mathrm{pH}$ 
phosphate buffer at $230 \mathrm{~nm}$. The method shows the linearity of concentration range of $2.5 \mu \mathrm{g} / \mathrm{ml}$ with a correlation coefficient of 0.998 .

\section{References:}

[1] Subal Chndra Basaks, Kesevan Senthil Kumar, Murugesan Ramalingam: Design and release characteristics of sustained release tablet containing Metformin $\mathrm{HCl}$ Revista Brasileria de Ciencias Farmaceuitics Brazilian Journal of Pharmaceutical sciences vol.44, n. 3, jul./set.,2008.

[2] Durgacharan A Bagwat, Pravin S kawtikwar, Dinesh M Sakarkar: Formulation and the in-vitro and biopharmaceutical evaluation of sustained release tablet of Verapamil $\mathrm{HCl}$ using precirol ATO 5through melt granulation technique. Asian Journal of Pharmaceutics-October-December 2009.

[3] Mario Grasil and Gabriele Grassi. Mathematical Modeling and Controlled Drug Delivery: Matrix Systems current drug delivery,2005, 2,97-116.

[4] Papadokostaki K.G Experimental realization of sustained simple kinetic regimes of particulate solutes subject to slow dissolution in the containing matrix journal of membrane science 326 (2009) 503-506.

[5] Ganesh Kumar, V.Juyal, P.P.Badoni. Formulation and evaluation of matrix tablets of Acarbose Ganesh Kumar et al / Drug Invention Today 2010, 2(5), 264-267.

[6] Sourabh Jain SK Yadav and UK Patil : Preparation and Evaluation sustained release matrix tablet of Furosemide using s natural occurring polymers. Research J. pharm. And Tech. 194):247-257.

[7] Debjit Bhowmik, Chiranjib.B, Sobharam Sahu, Chaya Sahu. Recent trends in Sustained Release Matrix Drug Dejivery System-an overview.

[8] Sahla Jamad, Reza Fassihi. Development of controlled release low dose class -2 drug glipzide. International Journal Of Pharmaceutics 312 (2006) 24-32.

[9] Alexandra Krajacic , Ian G. Tucker , matrix formation in sustained release tablets: possible mechanism of dose dumping. International Journal of Pharmaceutics 251 (2003) 67_/78

[10] K.Raghuram Reddy, Srinivas Mutalic and Srinivas Reddy once daily sustained release matrix tablets of Nicoandil : Formulation and in vitro Evaluation AAPS PharmSciTech 2003; 4(4) Article 61.

[11] (http://www.aapspharmscitech.org)

[12] Irupali Kale., Amrita Bajaj, Dolly Mathew. Development of Matrix Diffusion Controlled Drug Delivery System of Pentoxifylline. International Journal Of phamcy and Pharmaceutical sciences vol 2,Issue1,2010

[13] Saigal N, Baboota S, Ahuja A, Ali J. Microcrystalline Cellulose as a Versatile Excipient in Drug Research. J Young pharm vol 1 / No 12010

[14] S.Jamzad, R.Fassihi. Preformulation Characterization Of Glipizide As A Low Dose Drug In Controlled Release Drug Dekivery. 